\title{
Resistência parcial de cultivares antigas de macieira a Venturia inaequalis
}

\author{
Florian Blanchet ${ }^{1}$, Rosa Maria Valdebenito-Sanhueza² \& Piérri Spolti ${ }^{3}$ \\ ${ }^{1}$ Ecole Supérieure d'Agriculture, Rue Rabelais, 490007, Angers, França; ${ }^{2}$ Proterra Consultoria Agronômica Ltda., $95200-$ \\ 000, Vacaria, RS, Brasil; ${ }^{3}$ Laboratório de Epidemiologia de Plantas, Universidade Federal do Rio Grande do Sul, Av. Bento \\ Gonçalves, 91540-000, Porto Alegre, RS, Brasil
}

Autor para correspondência: Rosa Maria Valdebenito-Sanhueza, e-mail: rosamaria@proterra.agr.br

\begin{abstract}
RESUMO
Entre as práticas de manejo recomendadas para o controle da sarna da macieira (Venturia inaequalis), o uso de cultivares geneticamente resistentes assume grande importância em programa de manejo integrado, em que a restrição ao uso de fungicidas é comum. No presente estudo utilizaram-se técnicas de análise multivariada, com o objetivo de selecionar variáveis úteis nos programas de melhoramento e na classificação de cultivares de macieira quanto à resistência parcial a $V$. inaequalis. Dez cultivares originárias de material propagativo de plantas com idade entre 35 e 50 anos foram avaliadas. As cultivares CNPUV-09 e CNPUV-04 apresentaram nível de resistência similar à da cultivar Prima, padrão de resistência ao patógeno. A formação de estroma + apressório $(\mathrm{ST}+\mathrm{AP})$ e a esporulação (ESP) do patógeno após a inoculação com conídios em folhas das cultivares constituíram os maiores autovetores dos dois primeiros componentes principais e contribuíram com $23,9 \%$ e $28,5 \%$ da variância total, respectivamente. SP + AP e ESP apresentaram alta correlação com os eixos dos componentes principais. Essas variáveis podem ser úteis em programas de melhoramento de macieira para a seleção de cultivares com resistência parcial a $V$. inaequalis.
\end{abstract}

Palavras-chave: Análise de agrupamento, esporulação, estruturas de infecção, ordenação.

\begin{abstract}
Partial resistance of old apple cultivars to Venturia inaequalis

Among the practices recommended for apple scab (Venturia inaequalis) control, the use of genetically resistant cultivars is of great importance in integrated management programs, in which restrictions to fungicide use are common. In this study we used multivariate analysis techniques to identify variables useful in apple breeding programs for detecting partial resistance to $V$. inaequalis and to rank cultivars for this resistance type. A collection of ten old apple cultivars from propagative material 35 to 50 years old was evaluated for partial resistance to the pathogen. CNPUV-09 and CNPUV-04 had levels of resistance similar to that of cultivar Prima, the standard resistant cultivar. The stroma and apressorium (ST + AP) formation and sporulation (ESP) of the pathogen after a foliar inoculation by conidial suspension were the largest eigenvectors of the first and second principal components, and contributed with $23.9 \%$ and $28.5 \%$ of the total variance, respectively. ST + AP and ESP were highly correlated with first and second axes. These variables could be useful in apple breeding programs to select cultivars with partial resistance to $V$. inaequalis.
\end{abstract}

Key words: Cluster analysis, infection structures, ordination, sporulation.

A sarna da macieira, causada pelo fungo ascomicota Venturia inaequalis (Cooke) G. Wint. é um dos fatores limitantes ao cultivo de macieira (Malus domestica Borkh.) nas principais regiões produtoras do mundo, incluindo o Brasil. O fungo pode atacar folhas, flores, ramos e frutos, e a doença pode reduzir a produtividade dos pomares e a qualidade dos frutos em até $100 \%$, se não controlada (MacHardy et al., 2001).

O controle químico da sarna da macieira, a tática mais utilizada pelos produtores, inicia-se imediatamente após a brotação e pode chegar a um total de 9 a 15 aplicações de fungicidas durante o ciclo da cultura (Reardon et al., 2005). Entretanto, a demanda crescente dos consumidores por produtos com níveis adequados de resíduos, a cobrança social por sistemas de cultivo de menor impacto ambiental e a redução na eficiência dos fungicidas pela seleção de isolados de $V$. inaequalis resistentes geram a necessidade de buscar táticas alternativas e complementares para o manejo da doença (Jobin \& Carisse, 2007).

Apesar de haver grandes esforços em programas de melhoramento para a obtenção de cultivares resistentes a $V$. inaequalis, poucas são utilizadas em escala comercial. No Brasil, cerca de $90 \%$ do volume produzido de maçãs pertence às cultivares Gala e Fuji ou a variações clonais destas, todas suscetíveis à sarna da macieira (Oliveira et al., 2005). Entre os motivos da baixa adoção das cultivares resistentes se destaca a pouca durabilidade da resistência, uma vez que os programas de melhoramento no Brasil e no mundo têm focado a obtenção de cultivares com resistência controlada por genes de efeito maior (resistência vertical, 
monogênica) (MacHardy et al., 2001; Pereira et al., 2003). A resistência monogênica tem sido superada por novas raças de V. inaequalis (Parisi et al., 1993; Parisi \& Lespinasse, 1996; Schenatto et al., 2008).

A resistência parcial, controlada por múltiplos genes, é citada como uma alternativa mais adequada para a seleção de cultivares com resistência durável, pois os patógenos têm maior dificuldade de adaptação frente a uma resistência de bases genéticas mais amplas (Leonard \& Mundt, 1984). O paradoxo entre a potencial aplicabilidade da resistência parcial no manejo da sarna da macieira e a sua baixa adoção por parte dos programas de melhoramento está relacionado, entre outros aspectos, à complexidade na quantificação da resistência parcial, quando comparada à resistência monogênica (Xue \& Davidson, 1998). Tal fato se deve à dificuldade em definir padrões por análise univariada em dados multivariados (Sanogo \& Yang, 2004).

Assim, os objetivos deste estudo foram: i) avaliar a reação de cultivares de macieira a $V$. inaequalis pela mensuração de componentes de resistência parcial; ii) selecionar, por meio de análise multivariada, variáveis úteis aos programas de melhoramento na classificação de cultivares de macieira quanto à resistência parcial a V. inaequalis.

Dez cultivares de macieiras pertencentes ao banco de germoplasma da Embrapa Uva e Vinho foram utilizados neste estudo. Tais cultivares fazem parte de um programa de recuperação da base genética da macieira promovida por essa instituição, pela coleta e propagação de material junto a agricultores no estado do Rio Grande do Sul (Tabela 1) (Oliveira et al., 2005). Na coleta de materiais antigos foram retiradas gemas e enxertadas pelo método de borbulha sobre porta-enxerto Marubakaido com filtro M-9. No segundo ano, as seleções que mostraram menor suscetibilidade à mancha foliar foram multiplicadas ao mesmo tempo para avaliações quanto à suscetibilidade à sarna. Assim, apesar do material propagativo ser originário de plantas com idades distintas, todas as mudas, no momento das avaliações tinham dois anos de idade.

As cultivares Gala e Prima foram adotadas como padrões de suscetibilidade e resistência a $V$. inaequalis, respectivamente. A cv. Prima detém o gene Vf (Durel et al., 2003) que lhe confere a resistência ao patógeno, sendo adotada como cultivar parental em programas de melhoramento clássico da macieira no país.

As mudas foram cultivadas em vasos de $5 \mathrm{~L}$ com substrato orgânico e vermiculita (1:1) adubado na base com NPK e mantidas em casa de vegetação $(60 \%$ UR e $20^{\circ} \mathrm{C}$ ). Cada cultivar foi representada por três plantas em vasos individuais. A quebra de dormência foi realizada pela manutenção das plantas em câmara fria $\left(3^{\circ} \mathrm{C}\right.$ e $85 \%$ UR). Até o momento de utilização, o controle de oídio (Podosphaera leucotricha) e de pulgões (Eriosoma lanigerum) nas mudas foi realizado com aplicações mensais de enxofre e de fenitrothion. Trinta dias prévios ao início do estudo as plantas não receberam qualquer pulverização. A cada 15 dias durante a fase vegetativa as plantas foram adubadas com solução NPK (14-4-8).

Para as inoculações utilizou-se suspensão de conídios de três isolados de $V$. inaequalis pertencentes à coleção do Laboratório de Fitopatologia da Embrapa Uva e Vinho, tendo as seguintes origens: A58.3 - Monte Alegre, RS; A55.2 - Monte Alegre, RS; e A21.2 - São Joaquim, SC. Foram utilizados três isolados caracterizados previamente como pertencentes à raça 1 e patogênicos às cultivares Gala e Golden Delicious. A utilização dos três isolados foi adotada para assegurar a agressividade do patógeno. Os isolados foram cultivados em BDA com incubação em fotoperíodo de $12 \mathrm{~h}$ a $16^{\circ} \mathrm{C}$ por 15 dias, com o objetivo de obter conídios viáveis. A coleta dos conídios foi realizada pela adição de $1 \mathrm{~mL}$ de água destilada esterilizada (ADE) nas placas de Petri contendo cada um dos isolados. Os conídios foram retirados das colônias pela utilização de uma alça de Drigalsky esterilizada. A suspensão foi recuperada e centrifugada por $20 \mathrm{~min}$ a $4^{\circ} \mathrm{C}(8500 \mathrm{rpm})$. O sobrenadante foi descartado e o resíduo contendo os conídios foi mantido e diluído em $1 \mathrm{~mL}$ de ADE. Para cada isolado foi ajustada uma suspensão de 100 $\mathrm{mL}$ a uma concentração de $50 \times 10^{4}$ conídios $/ \mathrm{mL}$, a partir da qual foi obtida a suspensão mista (três isolados) para a inoculação por aspersão. Após a inoculação, as plantas foram mantidas em câmara de incubação a $18^{\circ} \mathrm{C}$ e fotoperíodo de $16 \mathrm{~h}$ durante todo o período de condução do experimento. Nas primeiras $48 \mathrm{~h}$ após a inoculação, a umidade relativa do ar foi ajustada para $100 \%$ e, em seguida, reduzida para $80 \%$

TABELA 1 - Características das cultivares antigas coletadas e pertencentes ao banco de germoplasma da Embrapa Uva e Vinho

\begin{tabular}{llcc}
\hline \hline Identificação & \multicolumn{1}{c}{ Origem } & Idade aproximada (anos) & Altura de copa (m) \\
\hline CNPUV-04 & Vacaria, RS & 50 & 4 \\
CNPUV-05 & Vacaria, RS & 50 & 4 \\
CNPUV-06 & Vacaria, RS & 50 & 4 \\
CNPUV-09 & Não-Me-Toque, RS & 35 & 4 \\
CNPUV-11 & Colorado, PR & 55 & 4 \\
CNPUV-16 & Muliterno, RS & 70 & 3 \\
CNPUV-17 & Muliterno, RS & 40 & 3 \\
CNPUV 18 & Muliterno, RS & 50 & 5 \\
\hline
\end{tabular}


com o objetivo de favorecer inicialmente a manutenção das gotas da suspensão nas folhas, seguida da evaporação. As folhas totalmente expandidas e inoculadas foram marcadas com fita adesiva sendo utilizadas as folhas $\mathrm{L}_{0}, \mathrm{~L}_{1}$ e $\mathrm{L}_{2}$ nos experimentos $\left(\mathrm{L}_{0}=\right.$ primeira folha totalmente expandida no ramo e assim sucessivamente).

Para a avaliação do processo de infecção, $66 \mathrm{~h}$ após a inoculação, 18 discos foliares de cada cultivar foram coletados a partir de seis folhas $\mathrm{L}_{2}$ (três discos/folha) e congelados a $-18^{\circ} \mathrm{C}$ para paralisar o processo de infecção. $\mathrm{Na}$ observação microscópica os discos foram descoloridos (eliminação da clorofila) e as estruturas fúngicas fixadas. Para tal, os discos foram imersos em solução de etanol e ácido acético (3:1) durante $2 \mathrm{~h}$ a $40^{\circ} \mathrm{C}$. Após a descoloração as estruturas do fungo foram coloridas com auxílio do corante azul de metil $(0,1 \%)$ durante 5 min e transferidos para solução de ácido fucsina $(0,2 \%)$ durante $5 \mathrm{~min}$. De cada disco foliar descolorido, 20 conídios foram coletados, avaliando-se a porcentagem de conídios não germinados (\%), apenas germinados (considerando um conídio germinado aquele com tubo de germinação com comprimento $\geq a 2 x$ o seu diâmetro), germinado e com formação de apressório, germinado e com a presença de estroma ou, finalmente, germinado com a presença de apressório e estroma.

Aos 18 dias após a inoculação, 18 folhas $\mathrm{L}_{0} \mathrm{e}$ $\mathrm{L}_{1}$ das cultivares foram avaliadas quanto à severidade de sarna com auxílio da escala de Parisi et al. (1994), a qual representa a percentagem da superfície foliar com esporulação de $V$. inaequalis. Também aos 18 dias após a inoculação, foi realizada a quantificação da esporulação do patógeno. Para isto dois discos foliares de diâmetro igual a $1 \mathrm{~cm}$ foram retirados de todas as folhas apresentando sintomas de clorose, necrose ou apenas esporulação. Os discos foliares foram imersos em ADE e agitados por 2 min em vórtex. A concentração de conídios na suspensão resultante foi determinada com auxílio de um hemacitômetro e os resultados expressos em número de conídios $/ \mathrm{cm}^{2}$.

A resistência parcial das cultivares foi caracterizada pelas variáveis: ESP (número de conídios por área foliar); NG (percentual de conídios não germinados); G (percentual de conídios apenas germinados); AP (percentual de conídios germinados e com formação de apressório); ST (percentual de conídios germinados e com formação de estroma); ST + AP (percentual de conídios germinados e com formação de estroma e apressório); INF CO (número de conídios infectivos por área foliar); e SEV (percentual da área foliar com sintomas de sarna da macieira).

Foi realizada análise descritiva e multivariada para caracterizar a variação entre as cultivares. A análise de correlação (coeficiente de Pearson) foi utilizada para definir a semelhança entre as variáveis e o índice de Gower para definir a semelhança entre as unidades amostrais (Legender \& Legender, 1998). Para a análise de agrupamento entre as cultivares foi adotado o critério de Ward (Dewney et al., 2003), tomando-se como ponto de seleção (número de grupos) a significância obtida pela auto-reamostragem (1000 permutações), em que tendo $P\left(\mathrm{G}^{\circ} \leq \mathrm{G}^{*}\right)>\alpha(\alpha=0,05)$ assume-se a nitidez do agrupamento $(\mathrm{P}=$ probabilidade; $\mathrm{G}^{\circ}=$ similaridade do agrupamento em k-grupos com a hipótese nula de nitidez, $\mathrm{G}^{*}=$ similaridade do agrupamento em k-grupos na amostra após o procedimento bootstrap; $\alpha=$ nível de significância) (Pillar, 1999a). A análise de componentes principais foi realizada para identificar quais as variáveis teriam maior influência na caracterização da reação das cultivares. Foram adotados como critérios na seleção das variáveis para facilitar a apresentação dos padrões obtidos aquelas que possuíam autovalores $\geq 1 \mathrm{e}$ variância total acumulada nos componentes principais sequenciais $\geq 70 \%$ (Mora-Aguilera \& Campbell, 1997; Alonso-Prados et al., 2003). A significância dos eixos selecionados foi avaliada pela auto-reamostragem (1000 permutações), em que para: $P\left(\theta_{i}^{\circ} \geq \theta_{\mathrm{i}}^{\circ}\right) \leq \alpha$ rejeita-se a hipótese nula e se assume a estruturação significativa dos eixos (Pillar, 1999b). No presente trabalho não foi adotado um limiar para $\alpha$ buscando evitar o erro do Tipo II pelo número relativamente baixo de unidades amostrais $(\mathrm{n}=80)$. Todas as análises estatísticas foram realizadas com auxílio do programa MULTIV versão 2.4.2 (Pillar, 2001) e a representação gráfica com auxílio do software SigmaPlot (versão 10 SPW7, SPSS Inc., Chicago, IL).

Os valores médios e os desvios padrões das variáveis relacionadas à resistência parcial das cultivares a $V$. inaequalis indicaram grande variação do germoplasma avaliado, mesmo com um número limitado de cultivares avaliadas. Entre as variáveis analisadas, a esporulação do patógeno e o número de conídios infectivos apresentaram os maiores desvios em relação à média global (Tabela 2).

A análise de componentes principais considerou todas as variáveis de resistência parcial citadas anteriormente e identificou a influência relativa destas na classificação das cultivares de macieira quanto à resistência a $V$. inaequalis (Tabela 3). Quando combinados, os componentes principais 1 e $2\left(\mathrm{CP}_{1}\right.$ e $\left.\mathrm{CP}_{2}\right)$ acumularam $79,4 \%$ da variação total entre as cultivares. Ainda, os componentes principais 1 e 2 apresentaram autovalores superiores ao do componente principal $3\left(\mathrm{CP}_{3}\right)$, o qual apresentou autovalor igual a 1,0 . Pelos critérios de seleção dos componentes principais citados, utilizou-se no presente estudo os dois primeiros componentes principais.

A esporulação e a formação de estroma e apressório pelos conídios, constituíram os maiores autovetores (valor absoluto) em $\mathrm{CP}_{1}$ e $\mathrm{CP}_{2}$, respectivamente, e contribuíram com $23,9 \%$ e $28,5 \%$ da variância total em cada componente principal (Tabela 3, Figura 1). Essas variáveis apresentaram os maiores valores absolutos de correlação com tais eixos, sendo iguais a 0,933 entre $\mathrm{CP}_{1}$ e esporulação e $-0,881$ entre $\mathrm{ST}+\mathrm{AP}$ e $\mathrm{CP}_{2}$ (Tabela 4). Nas correlações entre as variáveis univariadas destaca-se a relação entre a esporulação e o número de conídios infectivos e a severidade de sarna nas folhas, com coeficiente de correlação igual a 0,857 e 0,856 , respectivamente (Tabela 4). 
TABELA 2 - Média e desvio padrão de variáveis associadas à patogênese de Venturia inaequalis em folhas de dez cultivares de macieira inoculadas com mistura de três isolados do patógeno e mantidas em casa de vegetação

\begin{tabular}{lrr}
\hline \hline Variável & Média & Desvio padrão \\
\hline Esporulação $\left(\right.$ conídios/cm $\left.{ }^{2}\right)$ & 9391,0 & 12295,0 \\
Conídios não germinados (\%) & 33,9 & 4,7 \\
Conídios germinados (\%) & 19,7 & 6,1 \\
Conídios com apressório (\%) & 35,9 & 7,4 \\
Conídios com estroma (\%) & 1,9 & 0,9 \\
Conídios com apressório e estroma (\%) & 6,9 & 2,9 \\
Número de conídios com AP e ES (conídios $\left./ \mathrm{cm}^{2}\right)$ & 723,8 & 955,5 \\
Severidade $(\%)$ & 1,6 & 1,0 \\
\hline
\end{tabular}

TABELA 3 - Análise de componentes principais, baseada nos dados de todas as variáveis utilizadas, na avaliação de resistência parcial de 10 cultivares de macieira à sarna da macieira (Venturia inaequalis) em condições de casa de vegetação

\begin{tabular}{lccc}
\hline \hline Variável & $\mathbf{C P}_{\mathbf{1}}{ }^{\mathbf{x}}$ & $\mathbf{C P}_{\mathbf{2}}$ & $\mathbf{C P}_{\mathbf{3}}$ \\
\hline Autovalores & $3,632^{\mathrm{y}}$ & 2,721 & 1,013 \\
\% Variância & 45,403 & 34,012 & 12,657 \\
Esporulação (conídios $/ \mathrm{cm}^{2}$ ) & $\mathbf{0 , 4 8 9}$ & $-0,146$ & 0,023 \\
Conídios não germinados (\%) & 0,094 & 0,424 & $\mathbf{0 , 6 4 8}$ \\
Conídios germinados (\%) & 0,217 & 0,496 & $-0,327$ \\
Conídios com apressório (\%) & $-0,331$ & $-0,441$ & $-0,179$ \\
Conídios com estroma (\%) & 0,389 & $-0,090$ & $-0,525$ \\
Conídios com apressório e estroma (\%) & 0,045 & $\mathbf{- 0 , 5 3 4}$ & 0,357 \\
Número de conídios com AP e ES (conídios $\left./ \mathrm{cm}^{2}\right)$ & 0,473 & $-0,224$ & 0,118 \\
Severidade (\%) & 0,467 & $-0,123$ & 0,154 \\
\hline
\end{tabular}

${ }^{\mathrm{x}}$ Componentes principais; ${ }^{\mathrm{y}}$ Autovalores e variância associados aos componentes; ${ }^{\mathrm{z}}$ Autovetores das variáveis de resistência parcial das 10 cultivares de maçã a Venturia inaequalis, em que as variáveis em negrito correspondem a 23,9\%, 28,5\% e 42\% da variância dos descritores originais em cada um dos componentes, $\mathrm{CP}_{1}$ a $\mathrm{CP}_{3}$, respectivamente.

TABELA 4 - Coeficiente de correlação entre as variáveis de resistência parcial e componentes principais de 10 cultivares de maçã avaliadas à suscetibilidade ao fungo Venturia inaequalis

\begin{tabular}{|c|c|c|c|c|c|c|c|c|c|c|}
\hline Variável $^{\mathrm{x}}$ & $\mathrm{CP}_{1}$ & $\mathrm{CP}_{2}$ & Esp & NG & G & AP & ST & $\mathbf{S T}+\mathbf{A P}$ & INF CO & SEV \\
\hline $\mathrm{CP}_{2}$ & 0,000 & 1 & - & - & - & - & - & - & - & - \\
\hline ESP & $\mathbf{0 , 9 3 3 ^ { y }}$ & $-0,241$ & 1 & - & - & - & - & - & - & - \\
\hline $\mathrm{NG}$ & 0,180 & 0,700 & 0,019 & 1 & - & - & - & - & - & - \\
\hline G & 0,414 & 0,818 & 0,166 & 0,382 & 1 & - & - & - & - & - \\
\hline $\mathrm{AP}$ & $-0,631$ & $-0,727$ & $-0,376$ & $-0,742$ & $-0,806$ & 1 & - & - & - & - \\
\hline ST & 0,741 & $-0,148$ & 0,675 & $-0,239$ & 0,296 & $-0,306$ & 1 & - & - & - \\
\hline $\mathrm{ST}+\mathrm{AP}$ & 0,085 & $-0,881$ & 0,236 & $-0,372$ & $-0,781$ & 0,463 & 0,053 & 1 & - & - \\
\hline INF CO & 0,901 & $-0,369$ & 0,958 & $-0,011$ & 0,022 & $-0,304$ & 0,649 & 0,416 & 1 & - \\
\hline SEV & 0,891 & $-0,203$ & 0,857 & 0,052 & 0,207 & $-0,430$ & 0,515 & 0,305 & 0,856 & 1 \\
\hline
\end{tabular}

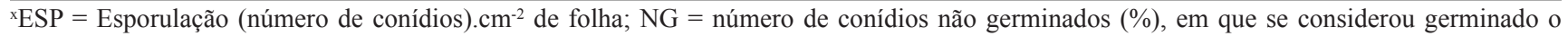
conídio com tubo de germinação de tamanho inferior ao maior diâmetro do esporo; $\mathrm{G}=$ conídios germinados (\%) em oposição ao expresso no item seguinte; $\mathrm{AP}=$ conídios germinado com a formação do apressório (\%); ST = conídios germinados com a formação do estroma (\%); ST + $\mathrm{AP}=$ conídios germinados com a formação de apressório e estroma (\%); INF CO = número de esporos efetivos, dado pelo produto de ESP e ST + AP, pela importância de tais estruturas ao processo das infecções de $V$. inaequalis, SEV = severidade (\%) de sarna da macieira em folhas das cultivares. ${ }^{y}$ Coeficientes de correlação de Pearson entre as variáveis de resistência parcial e componentes principais. Valores em negrito correspondentes a correlações significativas $(P<0,05)$. 

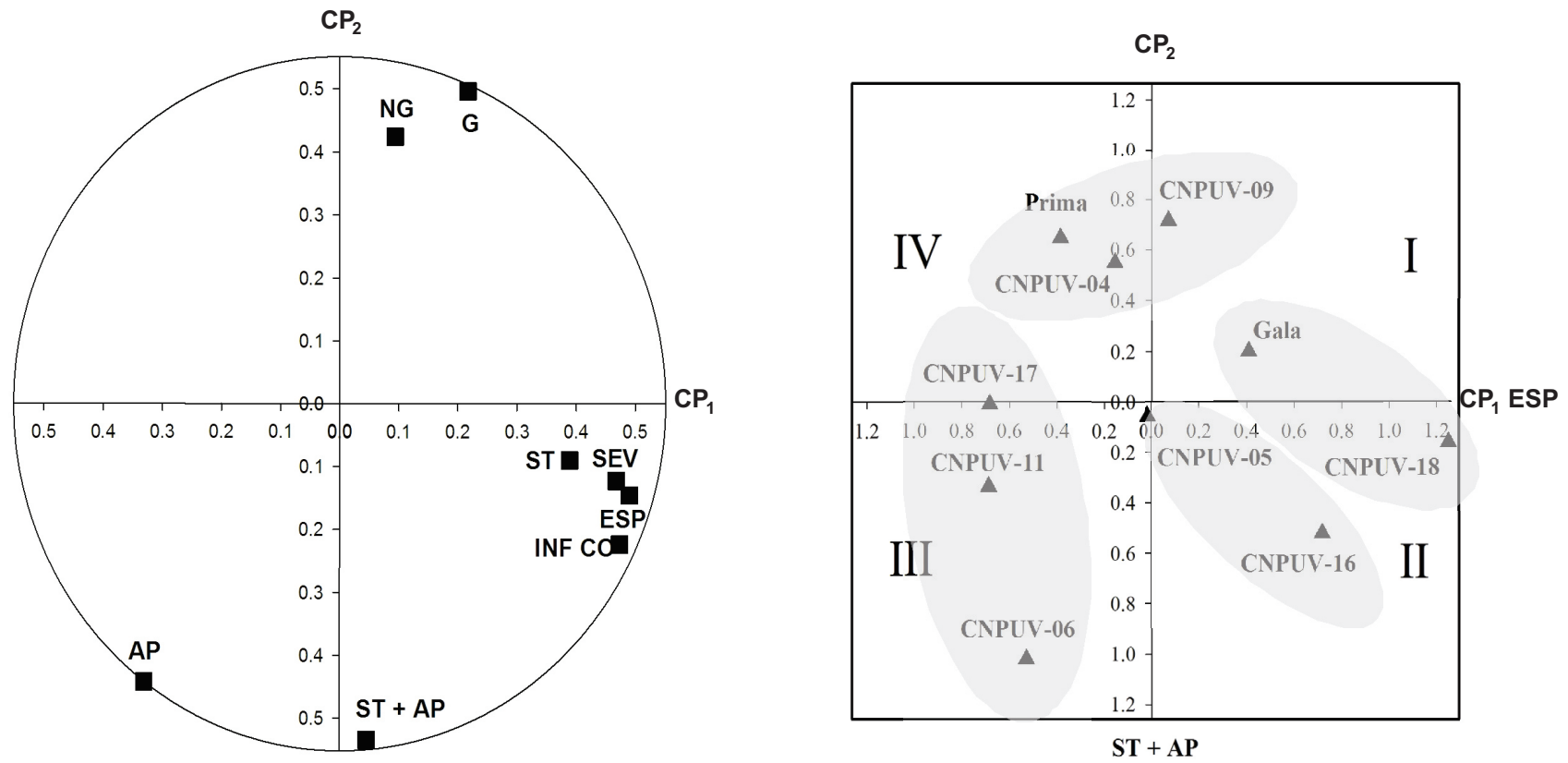

FIGURA 1 - Ordenação das variáveis associadas à resistência parcial de 10 cultivares de maçã a Venturia inaequalis como projetado nos planos $\mathrm{CP}_{1}$ e $\mathrm{CP}_{2}$ (esquerda) e agrupamento das cultivares de acordo com os fatores de resistência listados (direita). Os números de I a IV identificam os grupos (cluster analysis) em ordem de incremento da resistência parcial das cultivares ao patógeno.

$\mathrm{Na}$ análise de agrupamento foi possível distinguir quatro grupos nítidos de cultivares quanto à resistência parcial ao patógeno (Figura 1). As cultivares antigas CNPUV-09 e CNPUV-04 apresentaram resistência similar ao da cultivar Prima, padrão de resistência a $V$. inaequalis. Por outro lado, a cultivar CNPUV-18 apresentou comportamento similar ao da cultivar Gala (Figura 1). Assim, utilizando-se uma escala de resposta das cultivares ao patógeno, tendo por referência as cultivares Prima e Gala, as cultivares CNPUV-05 e CNPUV-16 poderiam ser classificadas como moderadamente suscetíveis, e as cultivares CNPUV-17, CNPUV-11 e CNPUV-06 como moderadamente resistentes a $V$. inaequalis (Figura 1). As cultivares resistentes caracterizaram-se pela baixa formação de estroma e apressório nos conídios germinados e baixa esporulação do patógeno nas folhas, situando-se no canto superior esquerdo do biplot (Figura 1). Por outro lado, as cultivares suscetíveis se situaram na parte positiva do $\mathrm{CP}_{1}$, pela correlação positiva entre ESP e $\mathrm{CP}_{1}$ e negativa entre $\mathrm{ST}+\mathrm{AP}$ e $\mathrm{CP}_{2}$ (Figura 1).

Em avaliações de suscetibilidade de cultivares de macieira a $V$. inaequalis são poucos os relatos de estudos de resistência parcial (Szkolnik, 1978; Olivier et al., 1984; Smith, 1992; Dewdney et al., 2003). O presente estudo diferencia-se pelo fato de utilizar como base de comparação cultivares antigas, coletadas junto a produtores, ao contrário dos estudos citados em que se tinham cultivares novas, em uso comercial.
Em avaliações de cultivares, vários componentes de resistência parcial têm sido considerados como, por exemplo, esporulação, intensidade da doença (incidência e severidade) e taxa de progresso de doença (Xue \& Davidson, 1998; Chongo \& Bernier, 1999). Entretanto, poucos são os casos em que as cultivares são avaliadas pela observação simultânea de todos estes componentes (Dewdney et al., 2003). A identificação de variáveis úteis em screenings de germoplasmas é uma das vantagens no uso da análise multivariada (Mora-Aguilera \& Campbell, 1997). Para Lebeda \& Jendrulek (1988), a análise multivariada é adequada para estudos de resistência parcial, pois, conforme Thompson \& Rees (1979), tal análise permite a classificação dos objetos (no caso cultivares) por um conjunto numérico de atributos (componentes de resistência parcial), procedimento incapaz de ser realizado pela análise univariada.

As cultivares CNPU-09 e CNPUV-04 apresentam níveis similares de resistência à cv. Prima. Entretanto como não se tem, até o momento, a descrição genética dessas cultivares antigas, tanto a possibilidade da presença do gene $V f$ nestas cultivares (Schenato et al., 2008), como a presença de outro(s) gene(s) relacionado(s) à resistência a este patógeno (Durel et al., 2003) devem ser consideradas como possíveis.

Como um dos principais fatores que contribuem para a disseminação da doença, a produção de esporos é considerada um importante componente de resistência 
parcial e para o progresso das epidemias (Parlevliet, 1979; Hartman et al., 1999). No presente estudo, assim como em trabalhos correlatos, a cultivar teve efeito significativo na taxa de esporulação (Szkolnik, 1978; Chongo \& Bernier, 1999; Dewdney et al., 2003).

Segundo Calenge et al. (2004), a utilização de aspectos associados ao processo de infecção, como a formação do estroma e apressório, tem sido pouco explorada na descrição da resistência parcial da macieira a $V$. inaequalis. Por exemplo, Dewdney et al. (2003) indicam o período de incubação e o período latente como componentes da resistência parcial no patossistema macieira - V. inaequalis. Pelos resultados obtidos neste trabalho podese afirmar que a esporulação e a formação de apressório e estroma podem ser adotados como parâmetros de avaliação de germoplasma de macieira quanto à resistência parcial a $V$. inaequalis. A facilidade relacionada à observação da formação das estruturas de $V$. inaequalis, à pequena quantidade de material vegetal necessária para a análise e à importância do estroma e, principalmente, do apressório na patogênese (Steiner \& Oerke, 2007; Schumacher et al., 2008), destaca a importância de tais características em avaliações de germoplasma no patossistema $M$. domestica vs. V. inaequalis.

\section{AGRADECIMENTOS}

Os autores agradecem ao Conselho Nacional de Desenvolvimento Científico e Tecnológico - CNPq, pelas bolsas concedidas; aos professores Valério DePatta Pillar e Emerson Medeiros Del Ponte, pelas sugestões na análise estatística e textual, respectivamente; e aos pesquisadores Dr. Paulo Ricardo Dias de Oliveira e Dr. João Bernardi, pela disponibilidade de mudas para o ensaio.

\section{REFERÊNCIAS BIBLIOGRÁFICAS}

Alonso-Prados JL, Luis-Arteaga M, Alvarez JM, Moriones E, Batlle A, Laviña A, García-Arenal F, Fraile A (2003) Epidemics of aphid-transmitted viruses in melon crops in Spain. European Journal of Plant Pathology 109:129-138.

Calenge F, Faure A, Goerre M, Gebhardt C, Van de Weg WE, Parisi L, Durel CE (2004) Quantitative trait loci (QTL) analysis reveals both broad-spectrum and isolate-specific QTL for scab resistance in an apple progeny challenged with eight isolates of Venturia inaequalis. Phytopathology 94:370-379.

Chongo G, Bernier CC (1999) Field and growth chamber evaluation of components of partial resistance to Colletotrichum truncatum in lentil. Canadian Journal of Plant Pathology 21:58-63.

Dewdney M, Charest J, Paulitz T, Carisse O (2003) Multivariate analysis of apple cultivar susceptibility to Venturia inaequalis under greenhouse conditions. Canadian Journal of Plant Pathology 25:387-400.

Durel CE, Parisi L, Laurens F, Van der Weg WE, Liebhard R, Jourjon MF (2003) Genetic dissection of partial resistance to race 6 of Venturia inaequalis in apple. Genome 46:224-234.
Hartman JR, Parisi L, Bautrais P (1999) Effect of leaf wetness duration, temperature, and conidial inoculum dose on apple scab infections. Plant Disease 83:531-534.

Jobin T, Carisse O (2007) Incidence of myclobutanil and kresoximmethyl insensitive isolates of Venturia inaequalis in Quebec orchards. Plant Disease 91:1351-1358.

Legender P, Legender L (1998) Numerical ecology. Amsterdam The Netherlands. Elsevier.

Lebeda A, Jendrulek T (1988) Application of methods of multivariate analysis in comparative epidemiology and research into field resistance. Journal of Plant Disease and Protection 95:495-505.

Leonard KJ, Mundt CC (1984) Methods for estimating epidemiological effects of quantitative resistance to plant diseases. Theoretical and Applied Genetics 67:219-230.

Machardy WE, Gadoury DM, Gessler C (2001) Parasitic and biological of Venturia inaequalis: relationship to disease management strategies. Plant Disease 85:1036-1051.

Mora-Aguilera G, Campbell CL (1997) Multivariate techniques for selection of epidemiological variables. In: Francl LJ, Neher DA (Eds.) Exercises in plant disease epidemiology. Saint Paul MN. APS Press. pp. 51-58.

Oliveira PRD, Valdebenito-Sanhueza RM, Bernardi J (2005) Coleta, avaliação e preservação de plantas antigas de macieira resultados iniciais. In: $3^{\circ}$ Congresso Brasileiro de Melhoramento de Plantas, Resumos... Gramado RS. SBMP.

Olivier JM (1984) Évolution de la lutte contre la tavelure du pommier. La Défense des Végétaux 225:22-35.

Parisi L, Lespinasse Y, Guillaumes J, Krüger J (1993) A new race of Venturia inaequalis virulent to apples with resistance due to the Vf gene. Phytopathology 83:533-537.

Parisi L, Lespinasse (1996) Pathogenicity of Venturia inaequalis strains of race 6 on apple clones (Malus sp.). Plant Disease 80:1179-1183.

Parisi L, Lespinasse Y, Guillaumes J, Krüger J (1994) A new race of Venturia inaequalis virulent to apples with resistance due to the Vf gene. Phytopathology 83:533-537.

Parlevliet JE (1979) Components of resistance that reduce the rate of epidemic development. Annual Review of Phytopathology 17:203-222.

Pereira AJ, Boneti JI, Brighenti E, Denardi F, Camilo AP (2003) Joaquina: nova cultivar precoce de macieira resistente à sarna. Agropecuária Catarinense 16:70-73.

Pillar VP (1999a) How sharp are classifications? Ecology 80:25082116.

Pillar VP (1999b) The bootstrapped ordination re-examined. Journal of Vegetation Science 10:895-902.

Pillar VP (2001) MULTIV: software para análise multivariada, testes de aleatorização e autoreamostragem "bootstrap". Porto Alegre RS. Departamento de Ecologia, Universidade Federal do Rio Grande do Sul.

Reardon JE, Berkett LP, Garcia ME, Gotlieb A, Ashikaga T, Badger $\mathrm{G}$ (2005) Field evaluation of a new sequential sampling technique for determining apple scab "risk". Plant Disease 89:228-236.

Sanogo S, Yang XB (2004) Overview of selected multivariate 
statistical methods and their use in phytopathological research. Phytopathology 94:1004-1006.

Schenato PG, Valdebenito-Sanhueza RM, Duarte V (2008) Determinação da presença da raça 1 de Venturia inaequalis no Sul do Brasil. Tropical Plant Pathology 33:281-287.

Schumacher CFA, Steiner U, Dehne HW, Oerke EC (2008) Localized adhesion of nongerminated Venturia inaequalis conidia to leaves and artificial surfaces. Phytopathology 98:760-768.

Smith CA (1992) Comparative studies on the components of innate partial resistance to Venturia inaequalis (Cke.) Wint. in nine apple cultivars. PhD Thesis, University of New Hampshire. Durham NH USA.
Szkolnik M (1978) Relative susceptibility to scab and production of conidia among 30 apple varieties. In: 1976-Apple and Pear Scab Workshop, Abstracts... Kansas City MO. American Phytopathological Society.

Thompson JP, Rees RG (1979) Pattern analysis in epidemiological evaluation of cultivar resistance. Phytopathology 69:545-549.

Steiner U, Oerke EC (2007) Localized melanization of appressoria is required for pathogenicity of Venturia inaequalis. Phytopathology 97:1222-1230.

Xue AG, Davidson CG (1998) Components of partial resistance to black spot disease (Diplocarpon rosae Wolf) in garden roses. Hortscience 33:96-99. 